\title{
Estado actual de la investigación en psicología de la ceguera
}

\author{
ESPERANZA OCHAITA y ALBERTO ROSA \\ Universidad Autónoma de Madrid

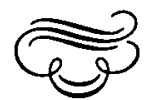 \\ Resumen
}

\begin{abstract}
En este articulo se presenta un resumen de la literatura psicológica sobre la ceguera, haciendo especial énfasis en las investigaciones realizadas por los autores y los restantes miembros del equipo de trabajo. Comienza con una introducción sobre las características fenomenológicas de la ceguera y continúa exponiendo el método que se utiliza para la investigación. Se concede especial interés a la descripción de las peculiaridades del desarrollo cognitivo de los invidentes. El trabajo concluye con la explicación de la lógica del presente temo monográfico dentro de la linea de investigación sobre psicología de la ceguera.
\end{abstract}

Palabras clave: Psicología de la ceguera, Desarrollo cognitivo.

\section{The state of the art of developmental psychology of the blind}

\begin{abstract}
This paper presents an outline of the current state of psychological literature on blindness. It starts with an intraduction on the phenomenological characteristics of blindness followed by an exposition of the method used by the authors and their research team. The central part of the article is devoted to a description of the cognitive development of the blind. The final part introduces the following articles within the logic that guides the authors on their research on the psychology of blindness.
\end{abstract}

Key words: Blind psychology, Cognitive development.

Agradecimientos: La mayor parte de las investigaciones a que se hace referencia en el artículo, han sido posibles gracias a las subvenciones obtenidas con cargo a los planes XI y XIII de la Subdirección General de Investigación Educativa del M.E.C. Actualmente la financiación que la C.A.I.C.Y.T. proporciona al proyecto tOntogénesis y microgénesis de la representación del entorno físico en las personas ciegass, nos permite continuar desarrollando el programa de investigación.

Dirección de los autores: Facultad de Psicología, U.A.M. Ciudad Universitaria de Cantoblanco. 28049. Madrid. 


\section{INTRODUCCION}

Las teorías psicológicas de carácter general normalmente se elaboran a partir de los datos empíricos obtenidos con sujetos considerados normales. Estos sujetos suelen ser adultos blancos, de clase media y de países occidentales desarrollados. Así, los sujetos que se salen de estos patrones, se consideran como casos especiales cuyas características se definen en comparación con la población «normals. Sin embargo, la investigación realizada con grupos especiales de población constituye un instrumento valioso para poner a prueba las teorías que pretenden tener una validez general para toda la especie humana. Un caso particular lo constituye la investigación psicológica que se lleva a cabo con sujetos que tienen minusvalías sensoriales.

El caso de los ciegos es de particular interés, ya que permite a los investigadores abordar el estudio de cuestiones tales como el papel que tienen las diferentes modalidades sensoriales en el acceso y representación de la información, así como analizar las consecuencias que tiene en el desarrollo cognitivo la utilización de esas modalidades. Por tanto, los trabajos de investigación en que se comparan los datos obtenidos por sujetos ciegos y videntes nos permitirán poner a prueba las teorías psicológicas en los aspectos que se acaban de citar.

Si todo ello se hace desde una perspectiva genética, asumiendo que buena parte de los procesos cognitivos dependen de procesos de desarrollo y aprendizaje que se producen en el curso del desarrollo ontogenético, esta investigación básica podría ayudar a desarrollar aplicaciones prácticas para la educación, no sólo de los niños con deficiencias visuales graves, sino también de los videntes.

Nuestro enfoque sobre la psicología de la ceguera asume que los ciegos no constituyen una población cuyas características tengan que describirse en contraste con la población considerada normal. Más bien pensamos que estos sujetos disponen de unos recursos físicos y psicológicos básicamente similares a los de los videntes, con la importante excepción de la vista. Esto no significa que un ciego tenga un funcionamiento psicológico equivalente al de un vidente con los ojos tapados, ya que la falta de visión da necesariamente lugar a una reestructuración del funcionamiento cognitivo así como al desarrollo de destrezas específicas. Se trata, por tanto, de una población con características cognitivas distintivas debidas al modo en que reciben y almacenan la información del ambiente.

Antes de analizar los datos empíricos, fijémonos por un momento en algunas de las características psicológicas de la ceguera. En primer lugar, el mundo fenomenológico de un ciego es muy diferente al de un vidente. Se trata de un mundo sin visión, sin colores, sin luz, en el que sentidos tales como el tacto, el oído y el olfato pasan a primer plano. El lenguaje les resulta imprescindible para comprender el mundo en que viven y a través de él pueden llegar a tener conocimiento de cosas con las que no pueden tener experiencia directa. Así pues, cuando abordamos el estudio psicológico de la ceguera, debemos intentar evitar el «visuocentrismo» para comprender lo que realmente es la ceguera y los rasgos psicológicos que la caracterizan.

Como ya hemos dicho, la falta de visión fuerza al ciego a utilizar sentidos que están infrautilizados en las personas videntes. Esto no significa asobrecompensación en el sentido de que tales sentidos proporcionen al invidente mayor cantidad de información, ya que los estudios realizados han demostrado que no existen diferencias entre los umbrales táctiles y auditivos de ciegos y videntes 
(Warren, 1978). Incluso un fenómeno aparentemente tan misterioso como el sentido del obstáculo, no es más que el aprovechamiento óptimo de la información auditiva, en el que pueden ser entrenadas las personas videntes (Warren, 1978).

El hecho de que ciegos y videntes tengan los mismos umbrales sensoriales no significa que sus procesos neurales y mentales sean idénticos. Los estudios electro-encefalográficos muestran que los ritmos eléctricos cerebrales son diferentes en ciegos y videntes. Parece ser que la carencia de estímulos retinianos aferentes en el lóbulo occipital produce cambios neurodinámicos que afectan a todo el cortex. En concreto, la actividad eléctrica de la zona central del cortex, especialmente el lóbulo izquierdo, sugiere la presencia de procesos compensatorios en los analizadores motores que se desarrollan con la pérdida de la visión (Zemtsova, 1969).

El conocimiento del espacio, tanto cercano (que el ciego puede abarcar con los brazos), como lejano (que en ausencia de la visión sólo es accesible mediante el movimiento y la propiocepción), es muy diferente en las personas ciegas y en las videntes. La carencia de visión supone un considerable problema a la hora de conocer el entorno y, aunque no vamos a extendernos más en este tema, al que dedicaremos un artículo en el próximo número, valga como ejemplo el hecho de que la perspectiva no existe como tal para un ciego de nacimiento.

El sistema perceptivo háptico tiene un papel fundamental en el conocimiento del mundo por parte del invidente. El término «háptico» fue primeramente utilizado por Revesz (1950), pero fue Gibson $(1962,1966)$, el primero que habló del sistema háptico como uno de los sistemas sensoriales, destacando su carácter activo e intencional. Kennedy (1978), en el mismo sentido que Gibson (1966), define el sistema háptico como: «... un modo posible de tocar, contactar y explorar, en el que la piel, los músculos y las articulaciones, funcionan juntos para obtener la información» (Kennedy, 1978, pág. 289). Este sistema tiene muchas características que lo diferencian del visual, aunque quizás las más importantes sean la secuencialidad y lentitud en la recogida de la información. A pesar de que, como afirma (Gibson, 1962), también la búsqueda de la información visual tiene un carácter secuencial, pudiendo hablarse de una «búsqueda táctil» como algo paralelo a la «búsqueda visual», la lentitud del tacto hace más evidente su carácter secuencial.

Nuestro programa de investigación, que viene desarrollándose desde hace ocho años, se ha diseñado desde la concepción de la ceguera que acabamos de exponer. Como vamos a ver a lo largo de estas páginas, sus objetivos fundamentales han consistido en estudiar el impacto que produce la carencia de visión en la representación mental y en la construcción de conceptos espaciales así como en saber cómo todo ello incide en el desarrollo cognitivo de los ciegos. Se han estudiado también otros aspectos relacionados con los anteriores, tales como la amplitud de memoria táctil y las características de la lectura braille.

\section{APROXIMACION METODOLOGICA}

Dado el enfoque sobre la psicología de la ceguera que se acaba de exponer, nuestra aproximación metodológica a su estudio tiene que ser, necesariamente, genética y diferencial. Todos nuestros trabajos - a los que nos referiremos en el apartado siguiente así como en los restantes artículos de este Tema Monográ- 
fico, comparten un diseño de estructura similar aunque, en ocasiones, metodología y las técnicas de obtención de datos sean diferentes.

La selección de los sujetos siempre se ha realizado mediante un diseño evolutivo transversal, es decir, escogiendo sujetos de diferentes niveles de edad, desde los primeros niveles escolares hasta la edad adulta, teniendo en cuenta los niveles de escolarización y el tipo de escuela a que asisten (ordinaria o especial).

Siempre que la tarea lo ha permitido, se han utilizado además de los ciegos, grupos de control de videntes, unos utilizando la visión y otros que realizaban las pruebas con los ojos tapados. Con esta distribución de sujetos se intenta controlar, en la medida de lo posible, los efectos que ejerce la modalidad sensorial con que se realiza la tarea, sobre el rendimiento. En todos los casos, los grupos de control han sido igualados con los experientales en las variables dependientes a que se ha hecho referencia en el párrafo anterior.

Los datos se han recogido mediante el método clínico piagetiano o mediante técnicas experimentales de laboratorio, dependiendo del tipo de tarea. En todos los casos se han cuantificado y sometido a análisis estadísticos.

\section{DESCRIPCION DEL DESARROLLO COGNITIVO DE LOS CIEGOS}

No existen en la literatura psicológica muchos trabajos sobre este tema y, de éstos, la mayoría se han realizado desde el marco teórico piagetiano. Desde este mismo marco teórico, se ha llevado a cabo una parte importante de nuestro propio trabajo. El panorama que surge de las investigaciones existentes es el siguiente.

Durante las dos primeras etapas del período sensoriomotor, el bebé ciego se desarrolla de forma semejante al vidente: ejercita los reflejos de los que está dotado desde el nacimiento y construye sus primeros esquemas de acción, a excepción, claro está, de los referentes a la visión. Es a partir de los cuatro o cinco meses cuando la evolución de los niños ciegos comienza a diferenciarse claramente de la de los videntes.

En ausencia de la visión, el niño ciego ha de sustituir los datos que ésta la proporciona sobre los objetos y el espacio donde éstos se sitúan por indicadores auditivos, con el consecuente problema que esto supone a la hora de construir un mundo de objetos permanentes y de un espacio independiente de la propia acción. En este sentido, los datos obtenidos por Fraiberg (1977) y Sonksen (1979), ponen de manifiesto que la coordinación entre la prensión y la audición no se produce en los niños ciegos hasta los 10 ó 12 meses, lo que supone un considerable retraso respecto a la coordinación visión-prensión en los videntes. Es precisamente alrededor del final del primer año de vida, cuando el bebé ciego comienza a buscar y a recuperar los objetos guiándose únicamente por el sonido que emiten.

Por lo que se refiere al desarrollo motor (Adelson y Fraiberg, 1977), las adquisiciones posturales de los bebés ciegos, si están bien estimulados, siguen una pauta semejante a la de los videntes. Pero, el inicio del gateo y la marcha están consideramente retrasados por la falta de motivación que supone la ausencia de estímulos del mundo exterior. Precisamente el comienzo del gateo coincide con el inicio de la búsqueda de los objetos por el sonido, situándose el comienzo de la marcha sobre los 19 meses.

Existen pocas investigaciones sobre ia adquisición de la función representativa en los niños invidentes. Fraiberg (1977), afirma que la adquisición de la permanencia de los objetos está retrasada entre uno y tres años en estos niños cuando 
se les compara con los videntes, y que tal retraso se debe a las dificultades que tiene la búsqueda de los objetos en el espacio en ausencia de la visión. Por otra parte, Fraiberg y Adelson (1977) señalan que la imitación de los niños ciegos es pobre y que el desarrollo del juego simbólico está considerablemente retrasado en los niños que carecen de visión. Es importante destacar que éste es uno de los aspectos del desarrollo de los invidentes en que se necesitan nuevas investigaciones.

Desde la perspectiva piagetiana, estas características especiales del desarrollo de la inteligencia sensoriomotora, deberían producir deficiencias importantes en las etapas siguientes del desarrollo cognitivo. Consideremos, por ejemplo la siguiente cita.

«El lenguaje, en efecto, no es más que un aspecto particular de la función semiótia o simbólica, y el sordo-mudo domina perfectamente sus otros aspectos (imitación, juego simbólico, imágenes mentales y lenguaje por gestos), lo que le permite prolongar sus esquemas sensoriomotores en esquemas representativos y llegar así a las operaciones antes que el ciego, cuyo esquematismo sensoriomotor $\mathrm{e}$ instrumentos figurativos padecen una mayor deficiencias. (Piaget et al., 1966).

Como vamos a ver a continuación, esta afirmación de Piaget ha resultado ser totalmente inadecuada.

Durante el primer año, el balbuceo prelingüístico presenta una evolución semejante al de los bebés videntes. Pero, hay que tener en cuenta que antes de que se inicie el lenguaje propiamente dicho, los niños ciegos han de tener problemas en la comunicación enactiva, sobre todo en relación con los objetos y sucesos que están fuera de su entorno táctil. Los datos con respecto a la aparición de las primeras palabras no están del todo claros. Autores tales como Frai: berg (1977), Warren (1984), Landau, B. y Gleitman, L. R. y Mills (en prensa) en sus revisiones sobre el tema señalan que, mientras algunos autores han encontrado un cierto retraso en los niños invidentes, otros consideran que, con una estimulación adecuada no tienen porqué producirse. En cualquier caso, entre los dos y tres años aproximadamente, el lenguaje de los invidentes puede considerarse normal, a excepción de la adquisición de los términos deícticos, tanto personales como espaciales (Mulford, 1980, citado en Mills, en prensa).

Por otra parte, hay que señalar que la carencia de visión plantea un serio problema respecto a la adquisición de la imagen del propio cuerpo. Tal problema se manifiesta tanto en el lenguaje, con un considerable retraso en la utilización de los pronombres «yo» y «mi», como en las posibilidades de autorrepresentación en el juego simbólico. Fraiberg y Adelson (1977), atribuyen estos problemas a la dificultad que el niño ciego tiene para adquirir una imagen de sí mismo.

La mayor parte de las investigaciones sobre el desarrollo cognitivo de los niños ciegos se ha centrado en el período de las operaciones concretas. Las características de esta etapa del desarrollo han sido también ampliamente estudiadas por nuestro equipo de investigación.

El punto de partida de las investigaciones sobre la etapa de las operaciones concretas en los niños ciegos lo constituye el trabajo de Hatwell (1966). Esta autora realizó un amplio programa de investigación con niños ciegos que residían en una escuela especial de París, estudiando la mayoría de las tareas que caracterizan este período del desarrollo.

Sus resultados mostraron que los niños ciegos presentaban un retraso de 3 ó 4 años en la realización de las tareas de operaciones infralógicas con compo- 
nentes espaciales, así como en las tareas lógicas de carácter manipulativo (clasificaciones, seriaciones y conservación de la sustancia). Por el contrario, ese retraso era casi inexistente en las pruebas que se hacían sobre una base predominantemente verbal (seriaciones verbales y problemas de clasificación que plantean inclusión). Además, en contraposición con las tesis piagetianas, encontró que los ciegos resolvían con éxito ambos tipos de tareas (verbales y manipulativas) aproximadamente dentro de los mismos niveles de edad (ver figura 1).

FIGURA 1

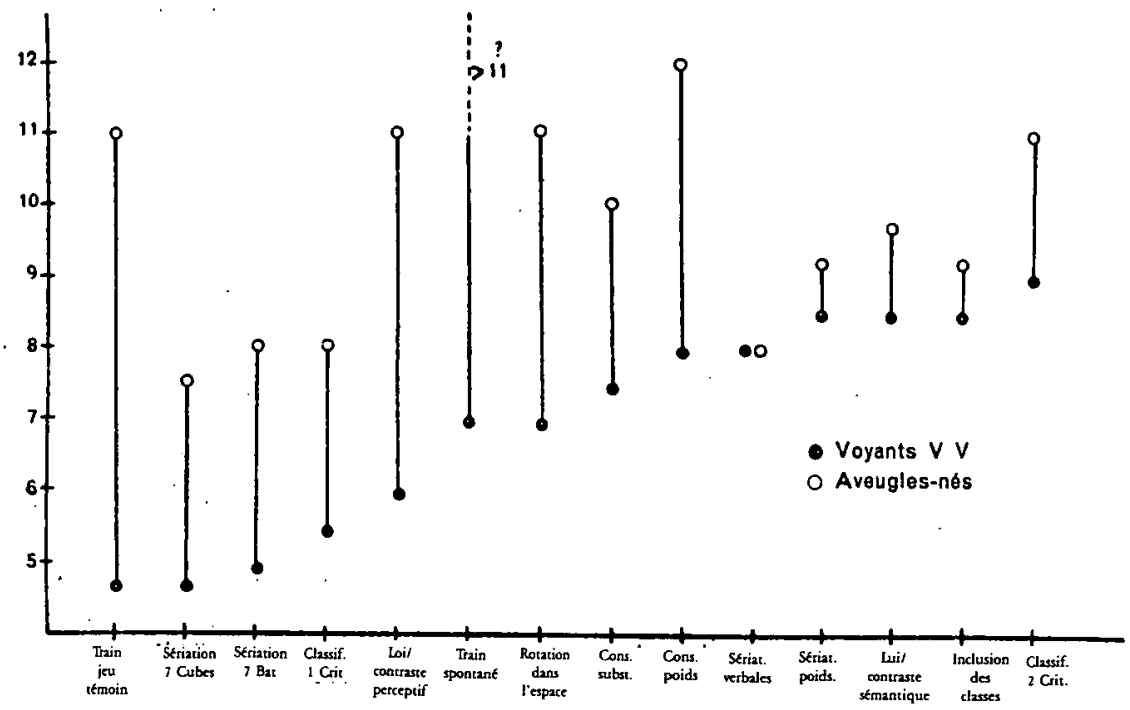

Tomado de Hatwell (1966)

Clasificación de las pruebas en función de la "edad media en las que son correctamente ejecutadas por los videntes $V V$

Otros autores han replicado posteriormente, algunos aspectos del trabajo de Hatwell (1966). Concretamente, Miller (1969), Gottesman (1973), Tobin (1972), Brekke et al. (1974), estudiaron las tareas de conservación. Sus datos confirmaron, en parte, los resultados de Hatwell, ya que mostraron que el retraso aumentaba en función de la gravedad de la deficiencia visual y de la edad en que se había producido. Estos autores también encontraron una moderada relación entre la variable «vivir en institución» y el grado de retraso en la adquisición de la conservación. Por su parte, Cromer (1973), no encontró diferencias entre ciegos y videntes en la realización de esta tarea. Resultados similares obtuvo Higgins (1973), con tareas de clasificación.

Precisamente, el carácter sorprendente de estos datos nos llevó a iniciar un amplio programa de investigación sobre las peculiaridades del desarrollo cognitivo de los niños ciegos. El primer proyecto (Rosa, 1980, 1981 a y 1981 b), se dedicó al estudio del desarrollo de las imágenes mentales desde una perspectiva piagetiana (Piaget e Inhelder, 1966). Los resultados pusieron de manifiesto la existencia de importantes retrasos en la adquisición de la representación por parte de los niños ciegos de nacimiento. Tales retrasos desaparecerían aproximadamente a los 11 años.

Posteriormente, investigamos la adquisición de las operaciones espaciales básicas (Ochaita, 1982 y 1984), con tareas de espacio topológico, proyectivo y eucli- 
FiĞŨRA 2

Primeros niveles de edad en los que cada grupo realiza adecuadamente las tareas y en los que no bay diferencias significativas entre ellos.

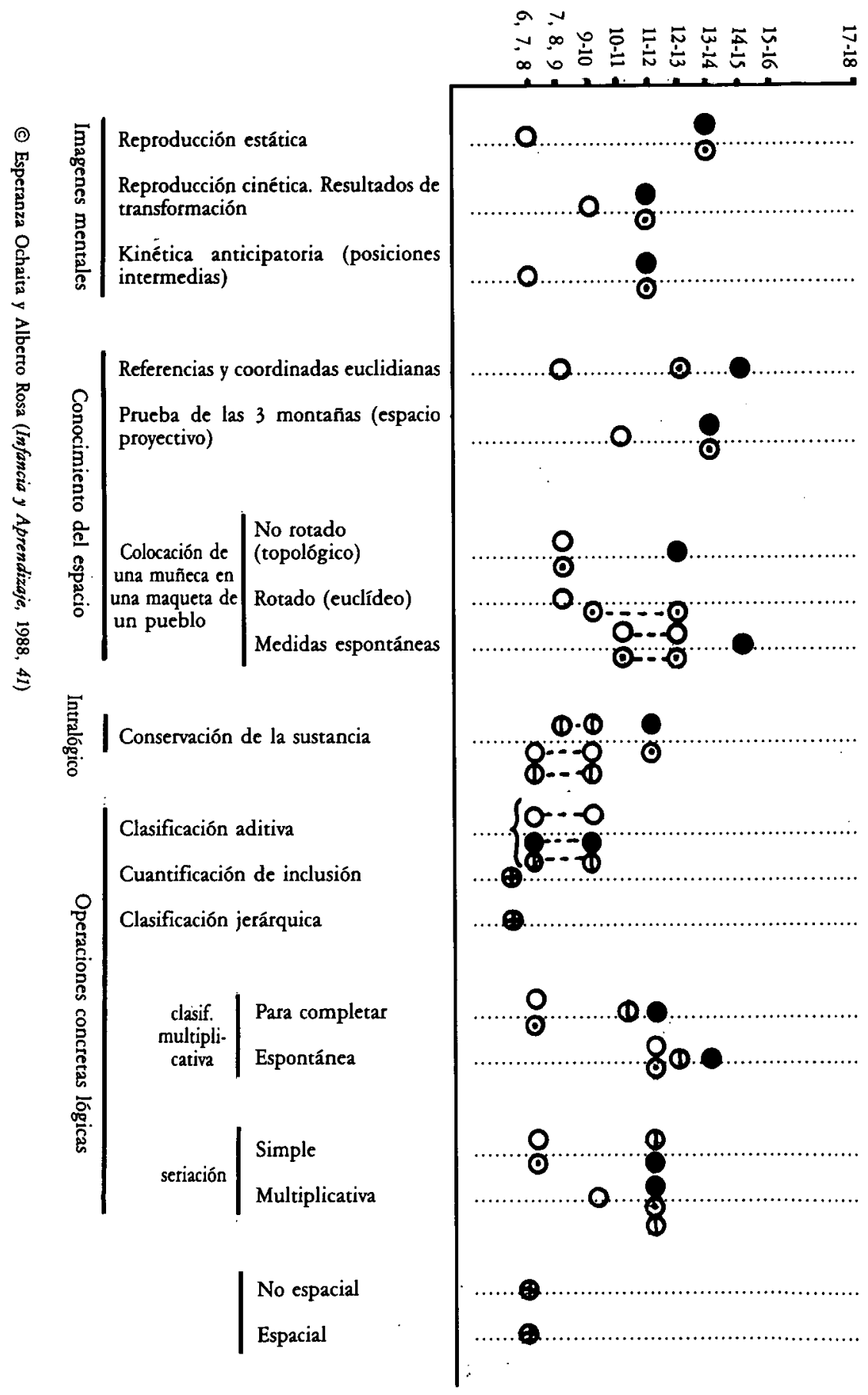

Ciegos OVidentes tapados $\boldsymbol{\Phi}$ Ciegos integrados $\mathbf{O}$ Videntes $\odot$ Todos los s.s. 


\section{FiguRA 3}

Primeros niveles de edad en los que cada grupo realiza adecuadamente las tareas y en los que no bay diferencias significativas entre ellos

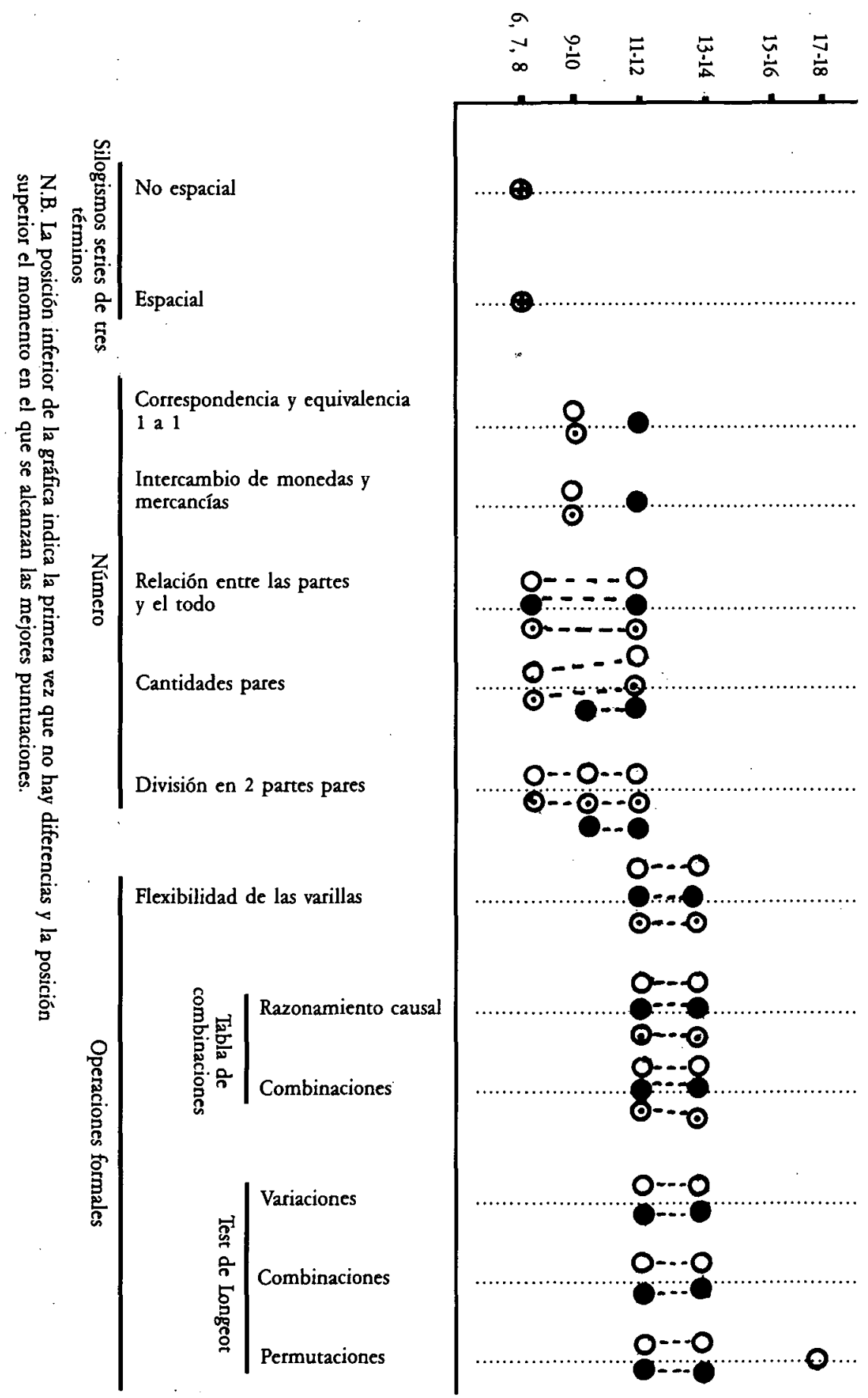


diano (Piaget e Inhelder, 1947; Piaget, Inhelder y Szeminska, 1948). En este caso se demostró que si bien los niños ciegos mostraban un retraso considerable respecto a los videntes de su misma edad (entre 5 y 8 años dependiendo de la prueba), tal retraso quedaba anulado sobre los 14 ó 15 años, incluso en las tareas más complejas. Estos datos concuerdan con los de otros autores que han estudiado el rendimiento de los ciegos en tareas complejas de espacio cercano, como Drummond, 1975.

Estos trabajos nos mostraron la conveniencia de estudiar de forma exhaustiva el desarrollo de las operaciones lógicas. Rosa et al., 1986; Ochaita et al., 1985, estudiaron el rendimiento de los ciegos en tareas tales como clasificación aditiva (con material manipulativo), inclusión de clases, clasificación jerárquica y cuantificación de la inclusión (fundamentalmente verbales), clasificaciones multiplicativas espontáneas y a completar seriación simple y multiplicativa con material manipulativo (varillas) o, seriación verbal (series de tres términos) y conservación de la sustancia (Piaget e Inhelder, 1941, 1967). Tales tareas se investigaron en niños ciegos de nacimiento que asistían a escuelas especiales (Rosa et al., 1986) así como en aquellos integrados en escuelas ordinarias (Ochaita et al., en prensa).

Los resultados (figura 2), mostraron que solamente existían retrasos por parte de los ciegos en las dos pruebas de seriación y en la clasificación multiplicativa a completar. Este retraso, de nuevo, desaparecería sobre los 11 años de edad.

Los niños ciegos integrados obtuvieron resultados muy semejantes. Al comparar su rendimiento con el de niños videntes de su misma escuela y nivel escolar, sólo se encontraron diferencias importantes entre ambos en las dos tareas de seriación, $y$, un cierto retraso de los ciegos en la clasificación multiplicativa a completar. Cuando comparamos el rendimiento de los dos grupos de ciegos, los que reciben educación integrada solamente obtuvieron mejores puntuaciones en las pruebas de clasificaciones multiplicativas y en la de conservación.

Merecen un comentario especial los datos de los niños videntes que realizaron las pruebas con los ojos tapados. Tanto sus resultados como la forma de manipular el material, fueron muy semejantes a los de los niños ciegos de nacimiento. Pensamos que su bajo rendimiento en comparación con el otro grupo de videntes no se debe sólo a la falta de experiencia en utilizar la modalidad sensorial táctil, aunque este factor debe tenerse en cuenta. Por el contrario, la coherencia de sus resultados con los de los sujetos ciegos parece demostrar que es la modalidad sensorial táctil la responsable de esta extraña distribución de adesfases». Por otra parte, hay un aspecto que merece destacarse en los resultados de estos sujetos. Cuando, a ciertos niveles de edad, una tarea resultaba fácil o familiar para los videntes tapados, sus rendimientos eran más parecidos a los del otro grupo de videntes que a los de los ciegos. Este fenómeno ya ha sido observado por otros autores y, en ocasiones, se ha explicado mediante la hipótesis de trasposición sensorial (Juurmaa, 1973), de acuerdo con la cual los sujetos videntes, en los casos anteriormente mencionados, son capaces de trasponer las percepciones táctiles a imágenes visuales, con las que están mucho más familiarizados.

Por último, pasemos a considerar el desarrollo de las operaciones formales en los invidentes, etapa del desarrollo en la que no existen datos anteriores a nuestros propios trabajos. Nuestro interés fundamental estaba en investigar si en tareas más complejas y en edades más avanzadas, seguiían produciéndose diferencias entre pruebas figurativas y verbales, y si el retraso en el desarrollo du- 
rante el período de las operaciones concretas tenía efectos en el pensamiento adolescente.

Se utilizaron pruebas de combinatoria y razonamiento causal (Piaget e Inhelder, 1955), tanto manipulativas como verbales. Los resultados (Pozo et al.., 1985; Rosa et al., 1986), no encontraron diferencias entre ciegos, videntes y videntes con los ojos tapados, en ninguno de los problemas estudiados (figura 3).

En resumen, los sujetos ciegos realizan considerablemente más tarde que los videntes las tareas que suponen habilidades de tipo espacial-manipulativo y que, supuestamente, se representan de forma analógica. Por el contrario, en las pruebas de carácter verbal, que pueden ser resueltas proposicionalmente, no existen diferencias en la edad de resolución por parte de ciegos y videntes. Por otra parte, la edad en que se resuelven ambas clases de tareas no coincide con lo que podría esperarse de la teoría de Piaget. En este sentido afirmaba Hatwell (1966):

«... esta emergencia contemporánea de las diferentes posibilidades lógicas en los ciegos tiene una significación particular: indica que las operaciones verbales parecen poder desarrollarse de una manera relativamente autónoma, y a pesar de un grave déficit de las operaciones con soporte concreto. Este fenómeno, bastante sorprendente, está no nólo en contradicción con la posición de Piaget, para quien la acción sobre los objetos constituye el punto de partida para todo conocimiento, sino también en contra de todo lo que la literatura psicológica y pedagógica (noción de ayudas concretas), ha aportado en este campo» (Hatwell, 1966, pág. 170).

¿Cómo puede explicarse este fenómeno? Precisamente, dedicaremos los siguientes artículos de este dosier a intentar completar aquellos aspectos del desarrollo de los invidentes que necesitaban una ulterior investigación, así como a explicar los factores que pueden ser responsables de las peculiaridades a que hemos hecho referencia. La mayor parte de este trabajo ha sido posible gracias a un proyecto de investigación financiado por el C.I.D.E. en el año 1984 (Ochaita et al., en prensa).

A continuación, se expone una investigación sobre la codificación de la información táctil en la memoria a corto plazo en las personas ciegas. Como más tarde veremos, los resultados de los trabajos que acabamos de citar y de las que se exponen a continuación, parecen indicar que algunas peculiaridades del desarrollo cognitivo de los ciegos pueden explicarse, en cierta medida, de acuerdo con las características de la percepción háptica y de las peculiaridades del procesamiento de este tipo de información en la memoria.

Seguidamente se exponen los resultados más relevantes de una amplia investigación sobre las peculiaridades de la lectura Braille. Nuestro interés por los procesos de lectura, nos llevaron a realizar el único trabajo de este tipo realizado en castellano, que puede resultar de indudable interés para las personas implicadas en la educación de los deficientes visuales. Por otra parte, desde el punto de vista teórico, los resultados están en estrecha conexión con las investigaciones sobre memoria táctil.

En el último artículo se discuten las peculiaridades del desarrollo cognitivo de los ciegos desde diversas alternativas teóricas, se analizan los factores explicativos que parecen más adecuados y se exponen las aportaciones de estos trabajos para la psicología cognitiva. 